\title{
Using Machine-Readable Text as a Source of Novel Vocabulary to Update the Dewey Decimal Classification
}

\author{
Carol Jean Godby \\ Ray Reighart \\ OCLC Online Computer Library Center, Inc.
}

\begin{abstract}
A technique is presented for automatically importing novel and emergent vocabulary into the Dewey Decimal Classification (DDC) from a domain-specific corpus of machine-readable text using insights from recent work by computational linguistics on word sense disambiguation. Results show that most of the vocabulary is mapped to the DDC hierarchy that is most appropriate for characterizing the domain.
\end{abstract}

\section{Introduction}

Several research projects at OCLC are exploring the potential use of the Dewey Decimal Classification as a tool for classifying and browsing collections of digital information. As argued in Vizine-Goetz (1996), the DDC is well suited to this task because it is a general classification scheme with hierarchical structures and a rich notation for ordering classes. The DDC is already widely used in English-speaking countries and is well positioned to serve as a browsing and retrieval tool for accessing information across international borders. Translations that closely preserve the meaning of the Dewey notation as specified in the English language standard edition now exist for over 30 languages, including Spanish, Russian, Italian, and Mandarin Chinese.

Nevertheless, like any substantial reference work, the DDC must keep pace with change. The ongoing editorial processes required to update the DDC are discussed in Mitchell $(1997,1998)$. Experimental efforts to enhance the indexing vocabulary of the DDC by mapping Library of Congress Subject Headings are described in Vizine-Goetz $(1997,1998 \mathrm{a})$. Our purpose here is to investigate the potential for importing additional indexing vocabulary to the DDC directly from machine-readable full text. This text documents the linguistic response to cultural change and is rapidly growing in volume and importance, as more full-text databases become available, as more electronic journals are published, and as the World Wide Web emerges as a new mass medium. Though the focus is on English-language text, the methods described here are theoretically extensible to other languages.

This project is a case study in a research program whose goal is to develop a library of generically useful software tools that identify subject-bearing terms and phrases and organize them by meaning, with or without reference to an external knowledge base such as the DDC (Godby 1998, Footnote 2). These tools should be able to facilitate access to stores of machine-readable text, primarily through better vocabulary identification, and can be used to create indexes and browse displays that more accurately represent an abstract view of the contents of a database. The same 
tools developed to solve the practical problems of indexing a database can also be used to support projects in classification research because the starting point in such work is the identification of terminology that refers to new concepts or represents new names for concepts. This work as fundamentally interdisciplinary, drawing insights from linguistics, information retrieval, and information science.

Here we extend the work reported in Vizine-Goetz and Godby (1996) and Godby (1996), where we argued that current indexing vocabulary obtained from machine-readable text could be imported into the DDC using an information retrieval model. Standard corpus-linguistics techniques (Daille 1994) were used to extract novel phrases such as virtual mall or Coldwell Banker from contemporary Internet resources, along with a paragraph or two of local context. This context was further processed to obtain a vector of words and phrases that are highly associated with the phrase of interest. For the first target phrase, the highly associated words words and phrases from the local context included Internet, online malls, marketplace, net, business, and shopping; and for the second target, highly associated words and phrases included agents, banker, and real estate. The list of associates for each target phrase was submitted as a query to Scorpion (see Footnote 1), a Web-accessible automatic classification system developed at OCLC that uses relevant fields from the DDC as a SMART database (Salton 1971). The processes required for importing novel vocabulary to the DDC from unrestricted text are shown schematically in Figure 1.

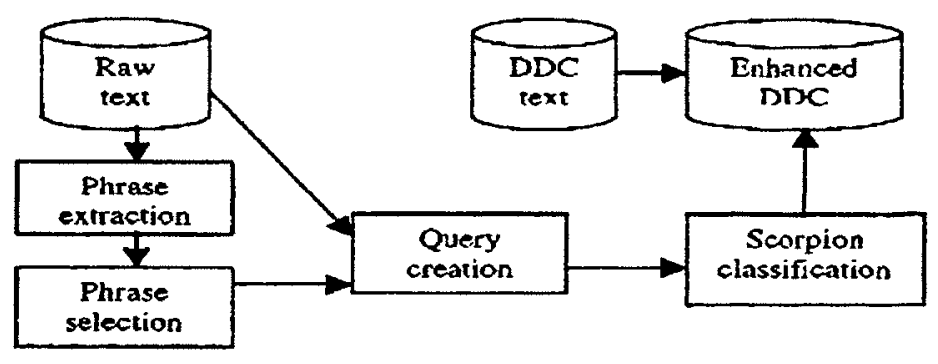

Figure 1. Process flow for mapping novel vocabulary obtained from free text to the DDC.

For a small set of hand-selected target phrases, the result was a list of DDC classes that suggested a reasonable domain of usage for the phrases. These DDC classes could, in turn, be enhanced with the target phrases as additional indexing vocabulary. Figure 2 shows the DDC classes returned by Scorpion for the two phrases. 


\section{Coldwell Bankex}

346.04373

332.6324

332.3322

\author{
Closing and settlements \\ Real estate \\ Real estate market
}

virtual mall

004.678

383.1

380.1

\author{
Internet \\ Retail trade \\ Commerce (Trade)
}

Figure 2. Top three DDC classes returned by Scorpion for a query created by the local contexts of Coldwell Banker and virtual mall.

Figure 3 shows a portion of an experimental version of a DDC record created by Vizine-Goetz (1998b) for the class 306.8742 Father-child relationship and illustrates how the processes described in this paper for importing terminology into the DDC from unrestricted text complements other efforts to enhance the DDC. The phrase fathers' rights was added using the process described above. The Library of Congress Subject Headings are obtained by a procedure described in Vizine-Goetz (1998a) that extracts statistical associations between the DDC and the LCSH from bibliographic records contributed to OCLC's Online Union Catalog to which DDC numbers and LCSH indexing vocabulary have both been assigned.

Enhanced DDC records like those in Figure 3 can be used by the DDC editors to guide their decisions in writing captions or adding indexing vocabulary to future editions of the DDC. These records can also be converted to an electronic version of the DDC that will have more vocabulary to support the use of the DDC as an online browsing tool or to create more responsive Scorpion databases.

Class Number: 306.8742

Class Name: Father-child relationship

\section{Dewey Hierarchv (structural information)}

Broader Classes

300 Social sciences

306 Culture and institutions

306.8 Marriage and family

306.87 Intrafamily relationships

306.874 Parent-child relationship

\section{Coordinate Classes}

306.8742 Father-child relationship

306.8743 Mother-child relationship

306.8745 Grandparent-child relationship

\section{Terminology}

\section{Dewey Index Terms}

Father and child

Fatherhood

Fathers

Fathers--family relationships

Teenage fathers

Teenage fathers--family relationships

Unmarried fathers

Unmarried fathers--family

relationships
Mapped Terms

LCSH/DDC (Dewey Web site)

Birthfathers

Free Text Terms

Fathers' rights

Statistically Associated LCSH

Fathers

Father and child

Fatherhood

Fathers and daughters

Figure 3. A DDC record with enhanced indexing. 
Our current goal is to import novel vocabulary to the DDC on a large scale, using as a test collection a 60-megabyte corpus of recent news articles from the domain of politics and current affairs. We use the same general procedure described in our earlier work but have focused on making improvements to the selection of terms and the preprocessing of documents.

We are interested in vocabulary that is automatically selected, not hand selected, as in our previous work. Our goal is to identify phrases, usually compound nominals or noun phrases modified by adjectives, that have achieved word-like status in a particular subject. In a corpus of news stories about politics, these phrases include alternative minimum tax, animal rights, ballistic missile defense, campaign finance reform and smart bombs but not old people, premature predictions, supply disruptions and welfare provisions. We refer to the phrases of interest as lexical phrases.

\section{Extracting lexical phrases from unrestricted text}

When writers compose text, they must balance two countervailing forces. On the one hand, their knowledge of the rules of grammar permits them to be creative, putting words together to form phrases in ways that have never been done before and may only infrequently be done again. On the other hand, they have a vast knowledge of the conventional ways that the concepts in their chosen subject have been referred to before, including the use of lexical phrases such as campaign finance reform. Since our goal is to increase access to textual databases through improved searching and browsing tools, we are far more interested in conventional usage than a writer's creative use of language because conventional expressions include the vocabulary of a given subject that writers and searchers are likely to share. Subject-rich terminology that consists primarily of noun phrases has been attested by computational linguists working with many languages spoken in Europe, North America, and the Pacific Rim. For some recent studies, see Bourigault, Jacquemin and L'Homme (1998).

Computationally tractable methods for harvesting lexical phrases from unrestricted text must overcome the obstacle that their defining property cannot be practically formalized. Like words consisting of single terms, lexical phrases are words because they are names for persistent concepts. This property cannot be captured easily in a formal system because it encodes a relation between language and the world. For example, school shooting is a name for a persistent concept because the American press has recently been obsessed by a spate of gun-toting schoolboys who opened fire on their classmates. Hotel shooting has an analogous meaning but is far less common because hotels are less popular or remarkable venues for crime.

Nevertheless, lexical phrases, like single words, have many distributional properties that can be measured. First, relative to syntactic phrases, lexical phrases are more frequent and their component words are highly associated by standard measures such as mutual information (Church and Hanks 1990). For example, given that missile appears in a corpus of news articles, the likelihood is high that ballistic precedes it. The same point can be made about animal rights, campaign finance, and Bill Clinton, but not about supply disruptions, premature predictions, or welfare provisions. 
Second, lexical phrases are highly specific to a single subject domain. Noun phrases such as community development or direct government spending are more commonly found in articles about political news than in articles about arts, health, or sports. However, phrases such as as ample evidence, old people or vice president, which might also be candidate lexical phrases because their component words are highly associated, appear in any number of contexts. This intuition was formalized in an algorithm by Zhou and Dapkus (1995), who isolated subject-rich phrases by comparing their relative frequencies in two corpora, one containing documents from a variety of subjects and one containing documents from a single subject.

Finally, lexical phrases form clusters based on syntactic similarity. Ranked frequency tabulations of noun phrase heads, the rightmost word in English phrases, successfully identify subject-rich lexical phrases in single-subject corpora and even in single documents, an observation that has been made for English (Godby 1998 and Wachtolder 1998), French (Ibekwe-San Juan 1998), and Japanese (Nakagawa and Kori 1998). In our experiments, the most common noun phrase heads in an English-language corpus about architecture were architecture and design, which appeared in phrases such as landscape architecture and urban design; in a corpus about metadata, the most common nominal heads were element and type, which appeared in the phrases metadata element, author element, Internet media type, and resource type.

Our procedure for identifying lexical phrases involves all three measures described above. The process flow is shown schematically in Figure 4.

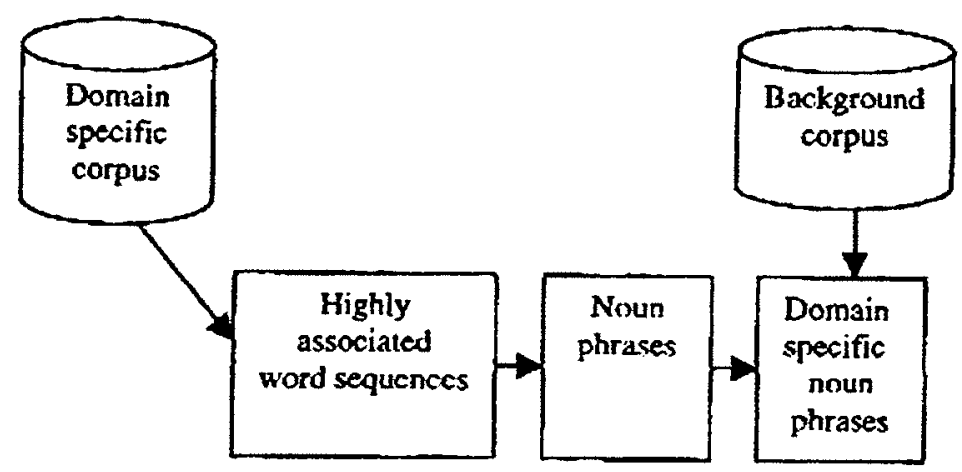

Figure 4. Process flow for obtaining domain-specific lexical phrases.

Using the processes outlined in Figure 1 on our test corpus, we collected 11878 lexical phrase candidates formed with 3987 different head nouns in an experimental run. The 15 most commonly occurring ones are listed in Table 1, along with counts of the lexical phrases containing them and some sample lexical phrases. Remarkably, just $15 / 3987$, or approximately $.04 \%$ of the head nouns, were the rightmost terms in over $14 \%$ of the lexical phrase candidates. This result supports the observation made by Nakagawa and Kori (1998) for a much smaller corpus of Japanese-language articles about computer science that many noun phrases in a domain-specific corpus share a relatively small number of unique heads. 
Table 1. The fifteen most commonly occurring noun phrase heads in a corpus of political news.

\begin{tabular}{|c|c|c|}
\hline Head & \multicolumn{2}{|c|}{$\begin{array}{l}\text { Lexical } \\
\text { phrases } \\
\text { containing } \\
\text { head }\end{array}$} \\
\hline program (-s) & 238 & $\begin{array}{l}\text { affirmative action programs, corporate welfare programs, } \\
\text { domestic spending program, housing programs, jobs programs }\end{array}$ \\
\hline $\operatorname{system}(-s)$ & 196 & $\begin{array}{l}\text { air defense system, ballistic missile system, child care system, } \\
\text { criminal justice systems, democratic system, electoral system }\end{array}$ \\
\hline policy (-ies) & 143 & $\begin{array}{l}\text { agricultural policy, commercial policy, conservative policy, drug policy, } \\
\text { energy policy, foreign policy, fiscal policy, global policy, technology policy }\end{array}$ \\
\hline issue (-s) & 125 & $\begin{array}{l}\text { abortion issue, campaign issues, character issue, foreign policy issues, } \\
\text { Korean nuclear issue, prison labor issues }\end{array}$ \\
\hline official (-s) & 121 & $\begin{array}{l}\text { American trade officials, Forest Service officials, law enforcement officials, } \\
\text { prison official }\end{array}$ \\
\hline plan $(-s)$ & & $\begin{array}{l}119 \text { affirmative action plan, benefit pension plan, Bosnian peace plan, } \\
\text { employee pension plans, health plans, Medicare reform plan }\end{array}$ \\
\hline committee (-s) & 117 & $\begin{array}{l}\text { budget committee, campaign committee, domestic policy committee, } \\
\text { House rules committee }\end{array}$ \\
\hline reform $(-s)$ & 115 & $\begin{array}{l}\text { banking reform, campaign finance reform, health care reform, electoral reform, } \\
\text { immigration reform, tort reform }\end{array}$ \\
\hline party (-ies) & 108 & $\begin{array}{l}\text { British Labour Party, Chinese Communist Party, Christian Democratic Pary, } \\
\text { Communist Party, Grand Old Party, Liberal Democratic Party, tea party }\end{array}$ \\
\hline government (s-) & 107 & $\begin{array}{l}\text { American Government, big government, Blair Government, } \\
\text { British Government, conservative government }\end{array}$ \\
\hline $\operatorname{tax}(-e s)$ & 97 & $\begin{array}{l}\text { alternative minimum tax, aviation fuel tax, business tax, college tuition tax, } \\
\text { corporate taxes, flat tax, wage tax, witholding tax }\end{array}$ \\
\hline chairman $(-m e n)$ & 95 & $\begin{array}{l}\text { Federal Reserve Board Chairman, Democratic Party Chairman, } \\
\text { Senate Banking Committee Chairman }\end{array}$ \\
\hline $\operatorname{act}(-s)$ & 87 & $\begin{array}{l}\text { American Dream Restoration Act, American Health Security Act, } \\
\text { Balanced Budget Act, Budget Reconciliation Act, Clean Air Act, } \\
\text { Emergency Food Assistance Act }\end{array}$ \\
\hline leader (-s) & 75 & $\begin{array}{l}\text { American leaders, black leaders, business leaders, evangelical leaders, } \\
\text { legislative leaders, new GOP leaders }\end{array}$ \\
\hline insurance & 66 & $\begin{array}{l}\text { American Mutual Life Insurance, auto insurance, bank insurance, } \\
\text { basic health insurance, casualty insurance, group health insurance, } \\
\text { individual health insurance, medical insurance, no-fault auto insurance, } \\
\text { private insurance, public health insurance, social insurance }\end{array}$ \\
\hline
\end{tabular}

The phrase selection processes described above allow at least three kinds of relatively low-risk mappings to the DDC.

- Mappings between real usage and controlled vocabulary. The lexical phrase auto insurance can be mapped to the DDC class 368.092 Motor Vehicle Insurance. Automobile insurance. Similarly, health plan(s) has been mapped to 368.382 Health Insurance, and flat tax has been mapped to 336.205 Tax Reform, to which the LCSH phrase flat-rate income tax--United States has also been mapped by techniques described in Vizine-Goetz (1998a). 
- Mappings of proper names to existing DDC categories. The DDC indexes already contain many proper names--not only the usual personal and geographic names, but also company names such as Microsoft. Names that are formed with commonly occurring head nouns, such as American Mutual Life Insurance and Grand Old Party, can be mapped to the DDC.

- Mappings of new concepts. The names for new concepts created by agents of cultural change are rarely coined words with no linguistic precedent. More commonly, they are lexical phrases that are formed by analogy with those already in common usage and whose component parts are probably represented in a modern classification system such as the DDC. Indeed, nearly all of the head nouns in Table 1 can be found in the DDC as captions or indexes that closely match the senses in which they are used in our test corpus. For example, the DDC class 368 Insurance, which contains index terms that enumerate types of insurance such as mortgage insurance and prepaid health insurance, could be augmented with the lexical phrases no-fault auto insurance, basic health insurance, and individual health insurance, all from our sample. As another example, the phrase health care exists in the DDC as a caption and an index entry, but health care reform and health care reform legislation do not, though reform and legislation are DDC classes that have been used by cataloging librarians to create custom DDC numbers for other topics of current interest such as welfare reform.

\section{Importing lexical phrases to the DDC}

To map lexical phrases to the DDC, we followed the same general procedure summarized in the Introduction and described more fully in Vizine-Goetz and Godby (1996) and Godby (1997). However, that procedure leaves considerable room for experimentation in the construction of queries. Intuitively, a query is simply a document containing the lexical phrase of interest that is submitted to the DDC version of the Scorpion database. If the query could be obtained from a canonical source, such as a dictionary definition or a paragraph in an encyclopedia, the DDC classes returned from Scorpion would be more likely to suggest reasonable domains of usage for the target phrases. But in our work, queries that simulate definitions of the target phrases must be constructed indirectly because the novel and emerging vocabulary that interests us is not defined in dictionaries and encyclopedias.

Our experiments with queries have been guided by recent results reported by computational linguists who have studied the problem of word sense disambiguation because the task of mapping new vocabulary to the DDC, however it is implemented, is an instance of the word sense disambiguation problem. As many have argued (see, for example, Yarowsky 1994), the word sense disambiguation problem has the same three essential parts that our problem has: words or lexical phrases whose senses or domains of usage are unknown, their citations or contexts of usage, and a lexical reference such as a dictionary, thesaurus, or classification system. A word is disambiguated when a similarity measure between the unknown word's contexts and a lexical reference results in a reasonable sense assignment. Consider, for example, the word line, a commonly studied word in the word sense disambiguation literature. A dictionary might list definitions for many senses, three of which are shown in Table 2: 
Line 1 - A theoretical mathematical construct that has length but no width.

Line 2 -- A fortified position, one marking the most forward position of troops.

Line 3 - Electrical cable used to connect computers, telephones, or televisions to power stations.

\section{Table 2. Three senses of the word line.}

If all of the citations for line are drawn from appliance manuals, they are likely to contain words such as electric, cable, or television and a similarity measure that compares the citation to the definitions in Table 2 would choose Line 3.

For word sense disambiguation to succeed, not only must the citation selected for the target word characterize one of its senses, but the lexical reference must also provide disjoint definitions. In the dictionary fragment given in Table 2, the electrical, military, and geometric senses of line are distinguished clearly enough that even a simple similarity measure which counts matching words in a target word's citation and the sense definitions might be able to choose the correct result. The DDC's definitions are also disjoint, as demonstrated by Thompson, et al. (1997). When they used the DDC's own classes as queries against a DDC database, the top-ranked result was the query itself for $97 \%$ of the 31,000 queries.

The task of constructing queries for the lexical phrases in the public affairs corpus has been simplified by the vocabulary selection process described in the previous section.

Since only domain-specific phrases are selected, they are far less ambiguous than single-term words, such as line, that are usually studied by researchers interested in word sense disambiguation. As Yarowsky (1994) observed, "frozen" expressions such as the lexical phrases in Table 1 usually exhibit only one sense in a text, an observation that also extends to the component words in lexical phrases. In Table 1, the head nouns program and system have many sense definitions in standard dictionaries, but their usage in a domain-restricted corpus such as ours is remarkably consistent. Nevertheless, ambiguity still exists. Our 60-megabyte corpus contains approximately 7000 documents, in which concepts such as health insurance are discussed from economic, medical, political, and social policy perspectives.

One of the most robust results from recent studies of word sense disambiguation is that reliable cues for identifying a word's sense or domain usage can be obtained from the smallest local environments in a citation: the sentence or clause that contains the target word (see, for example, Yarowsky 1993, 1994). This can be seen trivially for personal names in news articles, where titles and appositives are prevalent, as the examples from our data in Table 3 show:

Arizona senator John McCain

Attorney general Janet Reno

Deputy budget director Alice Rivlin

broadcaster Pat Robinson

cranky liberal Barney Frank

Syrian president Hafez Assad

White House spokesman Mike McCurry

Wisconsin governor Tommy Thompson

Table 3. Local contexts for personal names from a corpus of political news. 
Local contexts for lexical phrases whose head nouns are listed in Table 1 also show that the immediate syntactic context contains many clues that identify relevant perspectives. In sentences 1 and 2 in Table 4, the co-occurrence of tax code, tax break and economies of scale suggest that health insurance is discussed from an economic perspective. In sentences 3 and 4 , the co-occurence of government mistakes, state-run, and legislature are clues that health insurance is discussed from a political perspective.

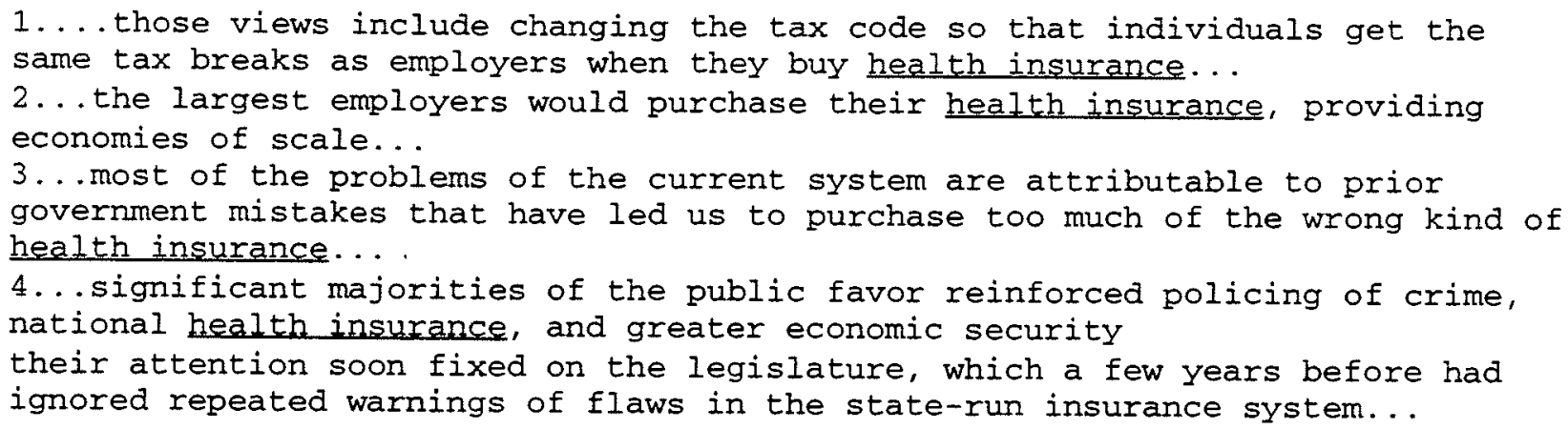

Table 4. Local contexts for health insurance in a corpus of political news

Following the recommendations in Grefenstette (1994), we collected all citations in the corpus containing the local syntactic context for each lexical phrase that to be added to the DDC. The contexts were parsed to extract noun phrases and verb phrases and submitted as queries to Scorpion.

Some lexical phrases in our corpus, such as health insurance, are already present in the DDC as captions or indexing vocabulary. These are valuable test cases because the classes to which they have been assigned by the DDC's editors can serve as convenient relevance judgments for information retrieval experiments on our system. To test the value of the additional processing described in this section, we constructed two sets of queries for a set of 50 such phrases. In the baseline condition, a query consisted of a single paragraph of raw text surrounding the target phrase. In the test condition, the citation was a single sentence surrounding the target phrase from which noun and verb phrases were extracted. For both conditions, recall was near $90 \%$ for 20 -item result sets. But in the test condition, approximately $60 \%$ of the relevant classes were among the top five results; in the baseline condition, only $20 \%$ were in the top five. These results suggest that the effect of more sophisticated preprocessing of queries is to move the DDC class assignments selected by human editors for the target phrases to the top of the result set, thus simplifying the challenging problem of filtering correct answers from inevitable noise.

Using the most successful procedure for constructing queries, we also experimented with the mapping of novel lexical phrases. Though relevance judgments do not exist for the novel lexical phrases, it is possible to gain insight into the performance of our system by examining the overall distribution of the Scorpion assignments. In preliminary tests, we automatically extracted and created queries for 272 of the most frequent phrases created from frequently occurring head nouns. As in previous tests, the queries were submitted to Scorpion to obtain DDC class 
assignments. Table 5 shows the distribution of the DDC-100 classes for the top-ranked result for each query. Nearly $88 \%$ of the assignments were to 300 Social sciences, the DDC hierarchy that would best characterize a corpus of political news.

\begin{tabular}{|c|c|c|c|c|}
\hline $\begin{array}{l}\text { DDC } \\
\text { Number }\end{array}$ & $\begin{array}{l}\text { DDC } \\
\text { Caption }\end{array}$ & Count & Percent & \\
\hline 000 & Generalities & & 2 & .007 \\
\hline 100 & $\begin{array}{l}\text { Philosophy, paranormal phenomena, } \\
\text { psychology }\end{array}$ & 3 & .011 & \\
\hline 200 & Religion & & 8 & .029 \\
\hline 300 & Social sciences & 239 & .878 & \\
\hline 400 & Langugage & 0 & - & \\
\hline 500 & Natural sciences and mathematics & 1 & .003 & \\
\hline 600 & Technology (applied sciences) & & 15 & .055 \\
\hline 700 & The arts & & 2 & .007 \\
\hline 800 & Literature (Belles-lettres) and $r$ & ric & 2 & .007 \\
\hline 900 & Geography, history, and auxiliary discip & $s 0$ & - & \\
\hline
\end{tabular}

Table 5. The DDC-100 class assignments of the top-ranked results for queries that characterize 272 lexical phrases obtained from a corpus of news articles about political affairs

Table 6 shows the distribution of the 239 top-ranked results that were assigned to the Social Sciences hierarchy. Over $80 \%$ of the novel lexical phrases were assigned to just four subhierarchies, 320 Political science, 330 Economics, 340 Law, and 350 Public administration and military science.

\begin{tabular}{|c|c|c|c|c|}
\hline $\begin{array}{l}\text { DDC } \\
\text { Number }\end{array}$ & Caption & & Count & Percent \\
\hline 300 & Social science & 6 & .025 & \\
\hline 310 & Collections of general statistics & 0 & - & \\
\hline 320 & Political science & & 74 & .309 \\
\hline 330 & Economics & 51 & .213 & \\
\hline 340 & Law & 36 & .150 & \\
\hline 350 & Public administration and military science & 31 & .129 & \\
\hline 360 & Social problems and services & 19 & .079 & \\
\hline 370 & Education & 11 & .046 & \\
\hline 380 & Commerce, communications, transportation & & 11 & .046 \\
\hline 390 & Customs, etiquette, folklore & 0 & - & \\
\hline
\end{tabular}

Table 6. Distribution of 239 top-ranked results assigned to the DDC 300 hierarchy for queries that characterize 272 lexical phrases obtained from a corpus of news articles about political affairs

Tables 7 and 8 show the same tight distribution of DDC class assignments in the top ten results returned for each query. Even with a result set that is an order of magnitude larger, nearly $84 \%$ of the assignments are still in the DDC hierarchy 300 Social sciences. 
Godby, C., \& Reighart, R. (1998). Using machine-readable text as a source of novel vocabulary to update the Dewy Decimal classification. 9th ASIS SIG/CR Classification Research Workshop, 91-106. doi:10.7152/acro.v9i1.12746

Proceedings of the 9th ASIS SIG/CR Classification Research Workshop

\begin{tabular}{|c|c|c|c|c|}
\hline $\begin{array}{l}\text { DDC } \\
\text { Number }\end{array}$ & Caption & & Count & Percent \\
\hline 000 & Generalities & & 43 & .016 \\
\hline 100 & $\begin{array}{l}\text { Philosophy, paranormal phenomena, } \\
\text { psychology }\end{array}$ & 35 & .013 & \\
\hline 200 & Religion & & 111 & .040 \\
\hline 300 & Social sciences & 2278 & .837 & \\
\hline 400 & Langugage & 4 & .001 & \\
\hline 500 & Natural sciences and mathematics & 23 & .008 & \\
\hline 600 & Technology (applied sciences) & & 186 & .068 \\
\hline 700 & The arts & & 27 & .010 \\
\hline 800 & Literature (Belles-lettres) and rhetoric & & 13 & .005 \\
\hline 900 & Geography, history, and auxiliary disciplines & 0 & - & \\
\hline Total & & 720 & & \\
\hline
\end{tabular}

Table 7. The DDC-100 class assignments of the top ten results for queries that characterize 272 lexical phrases obtained from a corpus of news articles about political affairs

Table 8 shows that even when larger result sets are examined, the lexical phrases are still primarily assigned to four of the ten subclasses in the Social Sciences hierarchy.

\begin{tabular}{llccc}
$\begin{array}{l}\text { DDC } \\
\text { Number }\end{array}$ & DDC & & Count & Percent \\
& & \multicolumn{1}{c}{ Caption } & & \\
300 & Social science & 47 & .020 & \\
310 & Collections of general statistics & 0 & - & \\
320 & Political science & 654 & .287 \\
330 & Economics & 338 & .148 & \\
340 & Law & 434 & .190 & \\
350 & Public administration and military science & 382 & .167 & \\
360 & Social problems and services & 201 & .088 & \\
370 & Education & 137 & .060 & \\
380 & Commerce, communications, transportation & 80 & .035 \\
390 & Customs, etiquette, folklore & 5 & .002 & \\
& & & &
\end{tabular}

Table 8. Distribution of 2278 top ten results assigned to the DDC 300 hierarchy for queries that characterize 272 lexical phrases obtained from a corpus of news articles about political affairs

Taken together, the data in Tables 5-8 provide evidence that DDC's class definitions are disjunct and support the argument that local syntactic context works remarkably well in identifying powerful clues for the domain usage of novel lexical phrases. Of course, the real test is the quality of the individual mappings, which can be evaluated only by classification experts or users who find the DDC enhanced with the lexical phrases introduced by the processes described in this paper valuable. Table 9 shows the top-ranked class returned by Scorpion for 20 lexical phrases. 
Godby, C., \& Reighart, R. (1998). Using machine-readable text as a source of novel vocabulary to update the Dewy Decimal classification. 9th ASIS SIG/CR Classification Research Workshop, 91-106. doi:10.7152/acro.v9i1.12746

Proceedings of the 9th ASIS SIG/CR Classification Research Workshop

\begin{tabular}{|c|c|c|c|c|}
\hline & DDC Caption & Upward & Hierarchy & \\
\hline$\frac{\text { Class }}{305.3}$ & & & & Lexical Phrase \\
\hline 305.3 & Men and women & 305 & Social groups & $\begin{array}{l}\text { gender gap, } \\
\text { gender preferences }\end{array}$ \\
\hline 320.5322 & Marxism-Leninism & 320.53 & $\begin{array}{l}\text { Collectivism and } \\
\text { fascism }\end{array}$ & Evil Empire \\
\hline 324.274704 & Republican party & 324.2 & Political parties & Grand Old Party \\
\hline 333.72 & $\begin{array}{l}\text { Conservation and } \\
\text { protection }\end{array}$ & 333.7 & $\begin{array}{l}\text { Natural resources and } \\
\text { energy }\end{array}$ & Clean Air Act \\
\hline 336.243 & Corporate income taxes & 336.24 & Income taxes & $\begin{array}{l}\text { corporate welfare, } \\
\text { corporate welfare } \\
\text { program, } \\
\text { alternative minimum tax }\end{array}$ \\
\hline 336.39 & Expenditure & 336.3 & $\begin{array}{l}\text { Public borrowing, } \\
\text { debt, expenditure }\end{array}$ & $\begin{array}{l}\text { jobs programs, } \\
\text { domestic sspending } \\
\text { programs }\end{array}$ \\
\hline 342.03 & $\begin{array}{l}\text { Revision and amendment } \\
\text { of the basic instruments } \\
\text { of government }\end{array}$ & 342 & $\begin{array}{l}\text { Constitutional and } \\
\text { administrative law }\end{array}$ & human life amendment \\
\hline 353.27 & Air defense system & 353.2 & $\begin{array}{l}\text { Military and defense } \\
\text { administration }\end{array}$ & air defense system \\
\hline 353.54 & Income maintenance & 353.5 & $\begin{array}{l}\text { Administration of social } \\
\text { welfare }\end{array}$ & social insurance \\
\hline 353.690973 & Health insurance & 353.6 & $\begin{array}{l}\text { Administration of health } \\
\text { services }\end{array}$ & Medicare reform plan \\
\hline 361.24 & Reform movements & 361.2 & Social action & immigration reform \\
\hline 363.58 & Programs and services & 363.5 & Housing & housing programs \\
\hline $\begin{array}{l}368.382 \\
368.4200973\end{array}$ & $\begin{array}{l}\text { Health insurance } \\
\text { Accident and health }\end{array}$ & 368 & Insurance & health plan \\
\hline & insurance (Medicaid) & 368 & Insurance & basic health insurance \\
\hline 658.3253 & Pensions & 358.32 & $\begin{array}{l}\text { Wage and salary } \\
\text { administration }\end{array}$ & employee pension plans \\
\hline 801.9 & Nature and character & 801 & Philosophy and theory & character issue \\
\hline
\end{tabular}

\section{Applications}

With the criteria we have defined to select phrases and create queries, it is feasible to map large amounts of vocabulary that represents current English usage to the DDC. This data can be used in a variety of ways. Our original intent was to add end-user indexing vocabulary to the DDC, supporting and extending the work of Vizine-Goetz (1996).

But the DDC can also be used in the background as an implicit structure that filters and supplements the automatic thesauri that can be generated from scratch by the informationretrieval and corpus-linguistics techniques explored by researchers such as Grefenstette (1994) and Croft and Yufeng (1994). Finally, our data is independently useful to the editors of the DDC because it automates some of the work performed by lexicographers. 
Godby, C., \& Reighart, R. (1998). Using machine-readable text as a source of novel vocabulary to update the Dewy Decimal classification. 9th ASIS SIG/CR Classification Research Workshop, 91-106. doi:10.7152/acro.v9i1.12746

Proceedings of the 9th ASIS SIG/CR Classification Research Workshop

\section{Acknowledgements}

We wish to thank the anonymous reviewer, whose comments resulted in many improvements to the style and substance of this paper.

\section{Footnotes}

1. Scorpion is accessible at: http://orc.rsch.oclc.org:6109/

2. The WordSmith project is accessible at: http://orc/WordSmith/wshome.html

\section{References}

Bourigault, D., Christian Jacquemin C., and L'Homme, M. (1998, August). Computerm '98: Proceedings from the First Workshop on Computational Terminology. Montreal, Quebec, Canada: COLING-ACL.

Church, K., and Hanks, P. (1990). Word association norms, mutual information,and lexicography. Computational Linguistics 16:1, 22-29.

Croft, B., and Yufeng, J. (1994). An association thesaurus for information retrieval. Intelligent Multimedia Information Retrieval Systems \& Management: Proceedings of the RIAO Conference. New York, New York. 146-160.

Daille, B. (1994). Study and implementation of combined techniques for automatic extraction of terminology. Proceedings from the Balancing Act. Las Cruces, New Mexico: the Association for Computational Linguistics. 29-36.

Godby, C. (1996). Enhancing the indexing vocabulary of the Dewey Decimal Classification. In the Annual Review of OCLC Research.

Accessible at http:/www.oclc.org/oclc/research/publications/review96/frames_man.htm

Godby, C. (1998a). The WordSmith Toolkit. The Annual Review of OCLC Research. Accessible at: http://www.oclc.org/oclc/research/publications/review97.

Godby, C. (1998b). English compound nominals in context. Unpublished manuscript. The Ohio State University.

Grefenstette, G. (1994). Explorations in Automatic Thesaurus Discovery. Boston: Kluwer Academic Press.

Ibekwe-San Juan, F. (1998). Building a prototype system for trends survey through the use of syntactic term variants. Computerm '98: Proceedings from the First Workshop on Computational Terminology. Montreal, Quebec, Canada: COLING-ACL. 22-28. 
Johnston, M., Boguraev, B., and J. Pustejovsky, J. (1995). The acquisition and interpretation of complex nominals. Working notes of AAAI95 Spring Symposium on the Representation and Acquisition of Lexical Knowledge. Accessible at: http://www.cs.brandeis.edu/ rllc/pub.html

Mitchell, J. (1997). DDC 21: An Introduction. In Dewey Decimal Classification Edition 21 and International Perspectives. Albany, New York: Forest Press, 3-15.

Mitchell, J. (1998, March/April). Dewey used around the world. OCLC Newsletter, 25-27.

Nakagawa, H. and Mori, T., (1998). Nested collocation and compound noun for term extraction. ). Computerm '98: Proceedings from the First Workshop on Computational Terminology. Montreal, Quebec, Canada: COLING-ACL. 64-70.

Salton, G.(Ed.) (1971). The SMART Retrieval System -- Experiments in Automatic Document Processing. Eglewood Cliffs, N.J.: Prentice Hall, Inc.

Thompson, R., Shafer, K., and Vizine-Goetz, D. (1997). Evaluating Dewey concepts as a knowledge base for automatic subject assignment. Presented at the First Digital Library Conference, Philadelphia. Accessible at: http:/orc.rsch.oclc.org:6109/

http://orc.rsch.oclc.org:6109/eval_dc.html.

Vizine-Goetz., D. (1996). Classification research at OCLC. In the Annual Review of OCLC $R \quad e \quad s \quad e \quad a \quad r \quad c \quad h$ A c c es s ib le http:/www.oclc.org/oclc/research/publications/review96/frames_man.htm

Vizine-Goetz, D. (1997). Popular LCSH with Dewey numbers (subject headings for anyone). In Annual Review of OCLC Research 1997. Accessible at: htttp://www.oclc.org/oclc/research/publications/review97.

Vizine-Goetz, D. (1998a May/June). Subject headings for everyone: popular Library of Congress subject headings with Dewey numbers. OCLC Newsletter, 29-33.

Vizine-Goetz, D. (1998b). Dewey as an Internet subject guide. Manuscript in preparation.

Vizine-Goetz. D. and Godby, C. (1996). Library classification schemes and access to electronic collections: enhancement of the Dewey Decimal Classification with supplemental vocabulary. Advances in Classification Research Volume 7: Proceedings of the 7th ASIS SIG/CR Classification Research Workshop, Silver Spring, MD: American Society for Information Science.

Wacholder, N. (1998). Simplex NPs clustered by head: a method for identifying significant topics within a document. The Computational Treatment of Nominals: Proceedings of the Workshop. Montreal, Quebec, Canada: COLING-ACL. 70-79. 
Yarowsky, D. (1993). One sense per collocation. In Proceedings of the ARPA Workshop on Human Language Technology. San Francisco: ARPA Software and Intelligent Systems Technology Office, Morgan Kaufmann, 266-71.

Yarowsky, D. (1994). Decision lists for lexical ambiguity resolution: application to accent restoration in Spanish and French. Proceedings of the 32nd Annual Meeting of the Association for Computational Linguistics, 88-95.

Zhou, J. and Dapkus, P. (1995). Automatic suggestion of significant terms for a predefined topic. In Proceedings of the Third Workshop on Very Large Corpora. 131-147. 
Godby, C., \& Reighart, R. (1998). Using machine-readable text as a source of novel vocabulary to update the Dewy Decimal classification. 9th ASIS SIG/CR Classification Research Workshop, 91-106. doi:10.7152/acro.v9i1.12746

Proceedings of the 9th ASIS SIG/CR Classification Research Workshop 